
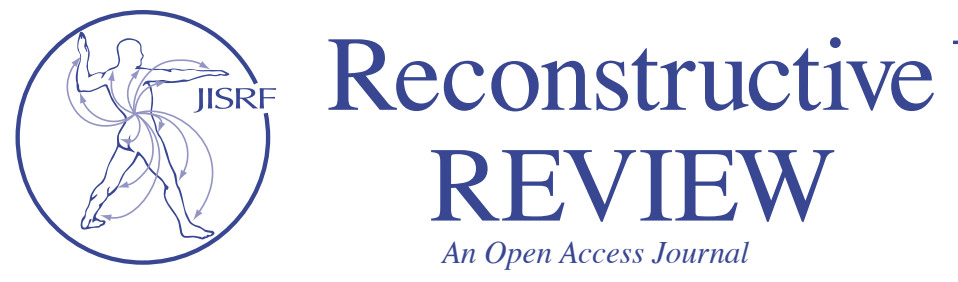

\title{
Long-Term Screening is Necessary in Patients with Metal on Metal Total Hip Arthroplasty
}

Martin $\mathrm{J}^{1}$, Odum $S^{1}$, Griffin $W^{1}$

\section{Abstract}

Background: Adverse reactions to metal debris with catastrophic failures have been seen with a number of metal on metal (MoM) total hip designs. Understanding survivorship and factors associated with failure will allow for more targeted surveillance of those patients at highest risk for failure. The purpose of this study was to assess the mid to long term survivorship and specific factors associated with failure for a large cohort of a single modular MoM design.

Methods: Consecutive patients treated with a modular metal on metal bearing with a five to fourteen year followup were included. Clinical outcome scores and radiographic data were prospectively collected. Failure was defined as revision of either component for any reason during the study period. Multiple implant, surgical, and patient factors were analyzed for associations with elevated ion levels or revision due to adverse reactions to metal debris.

Results: The average age at the time of surgery for the 253 patients included in the study was 55 . There were 28 revisions $(7.5 \%)$, eight due to metallosis $(2 \%)$. Survivorship was $89 \%$ at 12.6 years with revision for any reason as the end point. Survivorship was $93 \%$ when limited to revision for ALTR as the end point. Time in situ was the only variable that was statistically associated with an increased risk of failure due to ALTR $(\mathrm{p}<0.0001)$

Conclusion: In this large series of a single design modular metal-metal total hip we found relatively low rates of revision due to adverse reactions to metal debris. The only variable associated with a statistically significant risk of ALTR was time in situ. Therefore, long-term surveillance is necessary in patients with a MoM THA.

\section{Background}

Metal on Metal (MoM) total hip arthroplasty (THA) was widely used throughout the 2000's as an alternative bearing to metal on polyethylene. Potential benefits included decreased wear rates and the ability to utilize a larger femoral head size for improved stability $[1,2]$. However, following the initial enthusiasm with MoM THA, numerous studies began showing increased failure rates with MoM bearing implants. Specifically, increased implant failure due to adverse local tissue reactions (ALTR) likely related to the release of metal ions from the bearing surface [근 $]$. For this reason, several MoM THA designs were pulled from the market and or recalled $[\underline{3}, 6]$.

Currently, screening protocols to help with the early identification of ALTR rely on metal ion levels (Cobalt and Chromium), imaging studies, or some combination of the two. The definition of an "elevated ion level" remains controversial. In the UK, $7 \mathrm{ppb}$ is used as a trigger for further

Keywords: metal on metal; total hip replacement; screening protocols

Level of Evidence: IV 
evaluation, whereas Hart et al noted that ion levels above $4 \mathrm{ppb}$ were associated with abnormal bearing wear. Several studies have determined that ion levels alone should not be used as a trigger for surgery, but should be used in conjunction with patient symptoms, physical exam, radiographic evaluation, and the track record of the implant involved [ $[-11]$. Patients that are deemed to be at higher risk for ALTR should then proceed with cross sectional imaging using a MARS-MRI technique or Ultrasound evaluation to look for adverse reactions.

Multiple studies and registries have demonstrated a wide range of outcomes for the different MoM designs. The Australian registry has identified a $40 \%$ failure rate with the ASR THA at 10 years compared to $9.5 \%$ failure for the Pinnacle modular MoM. Multiple other studies have identified improved results with this same particular modular MoM THA design [11-13].

The FDA has recommended continued surveillance every two years for all patients with MoM THAs, regardless of design. It is likely that the majority of patients with a MoM bearing and low risk factors are being screened unnecessarily. Therefore, the following study was designed with two main goals: 1 . To report the long-term outcomes, including revision and reoperation rates, as well as metal ion levels of the Pinnacle modular two-piece MoM THA design, and 2. To determine if we can improve surveillance by targeting high risk patient populations of MoM THAs utilizing this data.

\section{Materials and Methods}

A query of our institutional total joint patient registry was performed to identify patients who have had a primary total hip replacement with a cementless, modular Pinnacle MoM implant, by a single surgeon, at a minimum of two years, postoperatively. 318 primary THA patients (457 hips) met the inclusion criteria. After obtaining IRB approval, data collection began by reviewing electronic health records. Patients who had not been seen in the clinic within the year prior to the start of the study were contacted to return for clinical exams. In addition to the routine clinical exam, metal ion levels were tested and standard radiographs were evaluated. Patients who were unable to return to the clinic were asked to complete a telephone interview that included a Hip Disability and Osteoarthritis Outcome Score (HOOS JR.) as well as questions regarding any component revision surgery. Patient retention methods included email, a letter, and three phone calls. If we were unable to reach the patient, they were defined as lost to follow up. The following data were collected: patient demo- graphic data (age, sex,), cobalt and chromium ion levels, femoral and acetabular component size, cup abduction angle, reason for revision surgery, and time in situ. The primary outcome variable was the need for revision total hip surgery. We also defined metallosis related failure as revision for ALTR or ion levels of $4.0 \mathrm{ppb}$ or greater.

Statistical Analysis: Standard descriptive statistics and analysis were carried out in SAS 9.4 (Cary, North Carolina). The distribution of the continuous variables was tested and found to be skewed. Therefore, a Wilcoxon two sample test was used to assess the bivariate association of continuous variables with failure. A Chi-square test was used with categorical variables with more than two response levels and a Fishers exact test was used to assess the bivariate association of binary variables with failure. Separate univariate logistic regression models were first fit to assess their association with failure related to metallosis (ALTR or elevated ion levels) with the intention of including significantly associated variables in a multivariate model for further assessment. A significance level of .05 was used to determine statistical significance for all statistical tests.

Study Sample Characteristics: Of the 318 patients with 457 hips identified, 253 patients (80\%) with 374 hips $(82 \%)$ were included. Twenty-six patients with 34 hips were deceased and 39 patients with 49 hips were lost to follow up. Of the 253 patients included, 149 were male (59\%) and the average age at the time of surgery was 55 years (20-78 years). The average time in situ for the 374 hips was 8.3 yrs.

The use of metal ion levels as a screening tool for MoM THAs was not routinely available until 2010.

With this in mind, many of our patients did not have ion levels measured during the first several years following their MoM THA.

\section{Results}

\section{Revision Rate and Survival}

Twenty eight of the 374 hips were revised for an overall revision rate of $7.5 \%$ and the revision rate for adverse local

Table 1: Reason for revision

\begin{tabular}{|l|c|c|}
\hline & Frequency & Percent \\
\hline Infection & 11 & 3 \\
\hline ALTR & 8 & 2 \\
\hline Instability & 4 & 1 \\
\hline Other & 3 & $<1$ \\
\hline Aseptic Loosening & 2 & $<1$ \\
\hline Total & 28 & 7.5 \\
\hline
\end{tabular}


tissue reactions (ALTR) was 2\% (8 of 374 hips). The most common reason for revision was infection $(\mathrm{n}=11,3 \%)$. Table 1 lists all of revision diagnoses.

\section{Survivorship Curves}

Survivorship was $89 \%$ at 12.6 years with revision for any reason as the end point. However, survivorship was $93 \%$ when limited to revision for ALTR as the end point. Survivorship decreased to $75 \%$ when failure included revision for ALTR and/or the patient had elevated metal ion levels Figure 1.

\section{Factors Associated with Metallosis Related Failure}

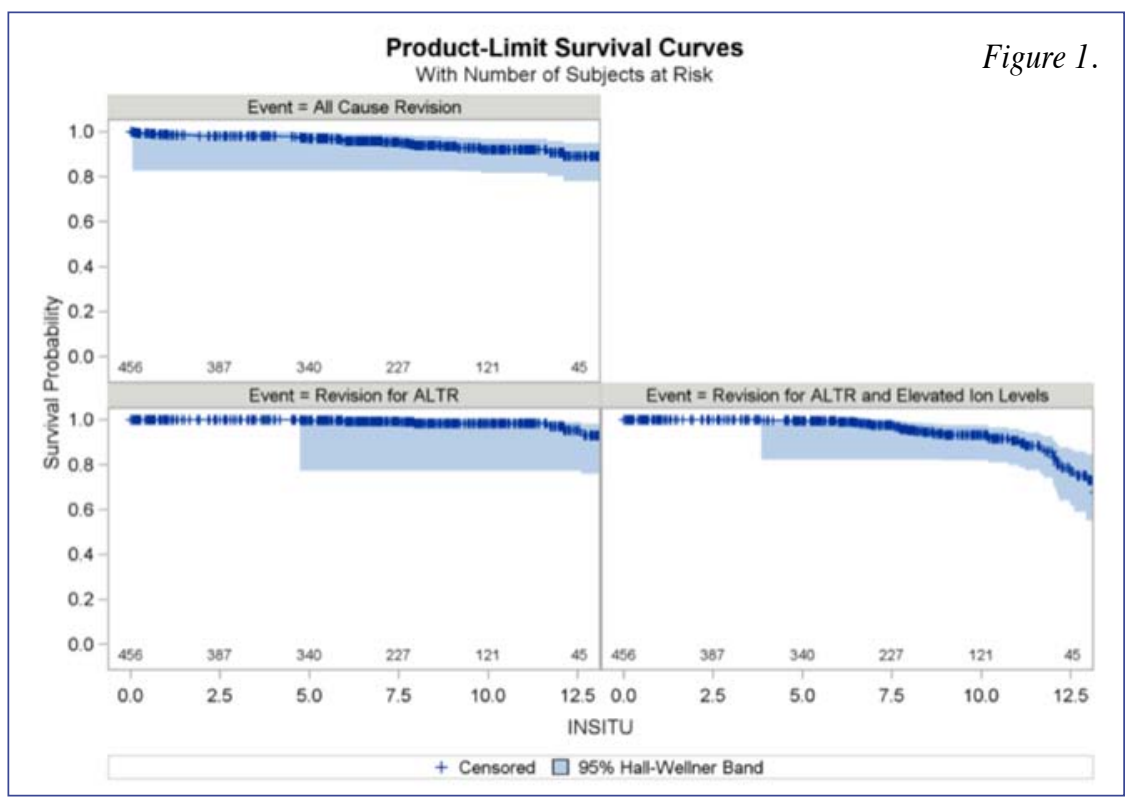

We evaluated patient and implant-related factors to determine if any were significantly associated with metallosis related failure defined as revision for ALTR or ion levels $>4.0$ (Table 2). There were no signifi-

Table 2: Univariate Analysis:

\begin{tabular}{|l|l|l|}
\hline & OR (95\% C.I.) & P-value \\
\hline Abduction Angle & $1.012(0.960,1.067)$ & 0.6539 \\
\hline Head Size & $0.939(0.833,1.059)$ & 0.3063 \\
\hline Cup Size & $1.056(0.969,1.151)$ & 0.2127 \\
\hline Age & $1.016(0.984,1.048)$ & 0.3347 \\
\hline Sex (ref. group Male) & $0.964(0.493,1.883)$ & 0.9143 \\
\hline Time in situ & $1.322(1.184,1.477)$ & $<0.0001^{* * *}$ \\
\hline
\end{tabular}

OR: odds ratio, C.I.: confidence interval, ref.: reference

*** Significant at the 0.001 probability level

cant associations between patient age or sex and the rate of metallosis related failure. Additionally, there were no significant differences in head size or cup abduction between those that had a metallosis related failure and those that did not. Time in situ was the only risk factor significantly associated $(\mathrm{p}<0.0001)$. Because only one variable, time in situ, was found to be significantly associated with failure at the bivariate level a multivariable regression model was not pursued.

Scatterplots were then constructed to evaluate how metal ions correlate with time in situ. The scatterplots in Figures 2 and 3 illustrate minimal positive correlations between cup abduction and time in situ and metal ion levels for unilateral patients only. As the time in situ increased the

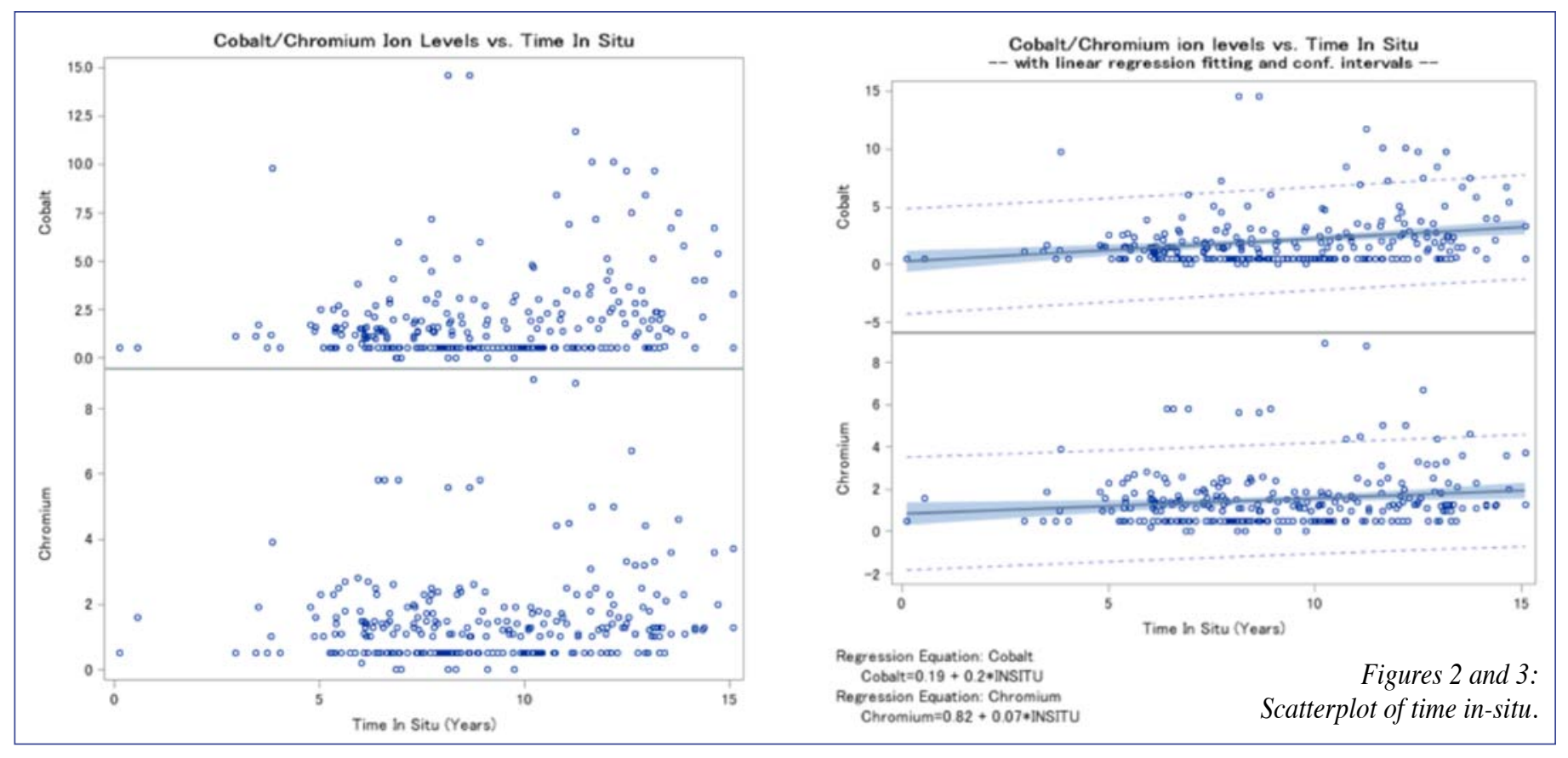


odds of failure significantly $(\mathrm{p}=.0008)$ increased (OR 1.39, 95\% CI 1.15-1.68). Best fit lines were included to graphically demonstrate an increase with time.

\section{Demographics of Patients with elevated metal ion levels}

35 patients were identified with elevated metal ion levels. There were 13 females and 22 males. The average cup abduction angle was 40 degrees and femoral head size and cup size were $36 \mathrm{~mm}$ and $56 \mathrm{~mm}$, respectively. 13 patients had both Chromium and Cobalt levels $\geq 4.0$, (range: Cobalt 4.7 - 14.6, Chromium 4.4 - 8.9). 2 patients had (only) Chromium levels $\geq 4.0$, (range: Chromium 5.8 - 5.8). 20 patients had (only) Cobalt levels $\geq 4.0$, (range: Cobalt 4.0 - 9.8).

\section{Demographics of patients revised for ALTR}

8 of 374 patients were revised for ALTR during this study. This group was comprised of 6 males and 2 females with an average age of 52. The average cup abduction angle was 41 degrees. The average femoral head size was 36 $\mathrm{mm}$ and cup size was $56 \mathrm{~mm}$. The average Co level was 7.67 and $\mathrm{Cr}$ level was 4.57.

Utilizing the grading system of Griffin et al, all intraoperative ALTRs received a score based on the extent of soft tissue necrosis [14]. (Grade $0=$ no metallosis; Grade $1=$ metallic staining, intracapsular fluid; Grade $2=$ extracapsular fluid; Grade 3 = extracapsular tissue necrosis). Of the 8 patients revised for ALTR, one patient had $1+$, four patients had $2+$, and three patients had $3+$ involvement.

\section{Discussion}

MoM THA has been largely abandoned in the United States due to concerns about adverse local tissue reactions related to metal ion release. Revision rates have been reported to be as high as $40 \%$ with the ASR cup at an average follow-up of 5 years [ $\underline{3}$ ]. Larger femoral head size has demonstrated significant elevations in metal ion levels [15]. However, not all MoM implants, have demonstrated these poor results. Specifically, the Pinnacle modular MoM design has demonstrated implant survivorship that is substantially better with a 7-year revision free survivorship of $97.8 \%$ [11]. The results of our study are also substantially better than other MoM designs with an 89\% survivorship at 12.6 years.

Screening protocols for patients with MoM THA are surgeon dependent, but commonly involve a combination of cobalt and chromium ion levels and cross-sectional imaging with MRI or US. However, there are numerous issues with these screening techniques. First, metal ion lev- els do not necessarily correlate with adverse local tissue reactions $[7,16]$. Second, the definition of "elevated" metal ion levels is not standardized. Cutoffs of $4.0 \mathrm{ppb}$ are commonly utilized, but ALTR can occur with levels under this. Finally, if a patient is identified with an "elevated" metal ion level, an MRI scan is commonly obtained. Fluid collections and or pseudotumors appear to be a common finding even in MoP and and CoP THA $[\underline{17}, \underline{18}]$. Furthermore, many of these lesions identified in MoM THAs have been demonstrated to decrease with time [19].

Currently, some advocate screening patients with a MoM THA every year with cobalt and chromium metal ion levels. Screening labs at our institution cost approximately 300 dollars per patient. 8 patients were identified and revised for ALTR during a 12.6 year time interval. For this study alone, the screening costs would be approximately 175,313 dollars to identify one patient with an ALTR, not including the costs of "elevated" levels where an MRI was obtained to confirm the diagnosis.

The results from this study indicate that the time in-situ was the only variable associated with an increased rate of failure. It is unclear what caused the late release of metal ions demonstrated in this study. The modular liner, bearing surface, or taper all represent potential sites of metal ion release, but without a formal analysis of the implants, we are unable to comment on the predominant source. Cup abduction angle, head size, sex, and patient age did not correlate with ion levels. Therefore, long-term follow-up is likely necessary for continuing surveillance in this patient population.

There were several limitations to this study. First, not all patients underwent a uniform screening protocol. Patients were implanted prior to our current understanding of the risks associated with MoM THAs. Therefore, screening protocols have changed with time and are not standardized amongst all surgeons. Secondly, serial ion levels were not included in this study. It is possible that metal ion levels that are initially low will remain low, whereas elevated levels may portend a worse prognosis and continue to trend upward. Finally, we have included only one implant, the Pinnacle two-piece MoM implant. This particular implant appears to have substantially improved results compared to other MoM implant designs and therefore this data is not necessarily applicable to all MoM THAs.

\section{Conclusion}

ALTR remains a challenging problem after MoM THA. However, we identified only 8 patients $(2 \%)$ who underwent revision secondary to ALTR at 12.6 years with the 
Pinnacle two-piece MoM design. Therefore, the vast majority of patients with this implant are being serially screened with a low probability of identifying an ALTR. Time in-situ was the only risk factor we identified that was associated with revision for ALTR. Therefore, improved screening protocols for MoM THA surveillance are necessary to improve detection and decrease cost.

\section{References}

1. Silverman EJ, Ashley B, Sheth NP. Metal-on-metal total hip arthroplasty: is there still a role in 2016? Curr Rev Musculoskelet Med [Internet]. 2016 Mar [cited 2017 Apr 24];9(1):93-6. Available from: http://www.ncbi.nlm.nih.gov/ pubmed/26791173

2. Williams D, Royle M, Norton M. Metal-on-Metal Hip Resurfacing. J Arthroplasty [Internet]. 2009 Jan [cited 2017 Apr 24];24(1):144-51. Available from: http:// www.ncbi.nlm.nih.gov/pubmed/18823742

3. Bernthal NM, Celestre PC, Stavrakis AI, Ludington JC, Oakes DA. Disappointing short-term results with the DePuy ASR XL metal-on-metal total hip arthroplasty. J Arthroplasty [Internet]. 2012 Apr [cited 2016 Jul 17];27(4):539-44. Available from: http://www.ncbi.nlm.nih.gov/pubmed/22000575

4. Clayton RAE, Beggs I, Salter DM, Grant MH, Patton JT, Porter DE. Inflammatory Pseudotumor Associated with Femoral Nerve Palsy Following Metal-on-Metal Resurfacing of the Hip: A Case Report. JBJS Case Connect [Internet]. 2008 Sep 1 [cited 2015 Jul 1];os-90(9):1988-93. Available from: http://www.ncbi.nlm.nih. gov/pubmed/18762660

5. Fricka KB, Ho H, Peace WJ, Engh CA. Metal-on-metal local tissue reaction is associated with corrosion of the head taper junction. J Arthroplasty [Internet]. 2012 Sep [cited 2016 Jul 17];27(8 Suppl):26-31.e1. Available from: http://www.ncbi. nlm.nih.gov/pubmed/22554728

6. Madanat R, Hussey DK, Donahue GS, Potter HG, Wallace R, Bragdon C, et al. Early Lessons From a Worldwide, Multicenter, Followup Study of the Recalled Articular Surface Replacement Hip System. Clin Orthop Relat Res [Internet]. 2016 Jan [cited 2016 Jul 17];474(1):166-74. Available from: http://www.ncbi. nlm.nih.gov/pubmed/26310677

7. Griffin WL. Metal ion levels: how can they help us? J Arthroplasty [Internet]. 2014 Apr [cited 2015 Aug 15];29(4):659-60. Available from: http://www.ncbi. nlm.nih.gov/pubmed/24655610

8. Smolders JMH, Hol A, van Susante JLC. Metal ion trend may be more predictive for malfunctioning metal-on-metal implants than a single measurement. Hip Int [Internet]. 2013 [cited 2017 Jun 28];23(5):434-40. Available from: http://www. ncbi.nlm.nih.gov/pubmed/23934907

9. Kiran M, Shivarathre D, Peter VK. Blood Metal Ion Levels Have Limited Utility in the Surveillance of Asymptomatic Large-Head Metal-on-Metal Total Hip Arthroplasties. J Arthroplasty [Internet]. 2017 Jul 20 [cited 2017 Sep 6]; Available from: http://www.ncbi.nlm.nih.gov/pubmed/28781016

10. Barrett WP, Kindsfater KA, Lesko JP. Large-diameter modular metal-on-metal total hip arthroplasty: incidence of revision for adverse reaction to metallic debris. J Arthroplasty [Internet]. 2012 Jun [cited 2017 Mar 20];27(6):976-83.e1. Available from: http://linkinghub.elsevier.com/retrieve/pii/S0883540312000630

11. Kindsfater KA, Sychterz Terefenko CJ, Gruen TA, Sherman CM. Minimum 5-year results of modular metal-on-metal total hip arthroplasty. J Arthroplasty [Internet]. 2012 Apr [cited 2017 Mar 20];27(4):545-50. Available from: http://linkinghub.elsevier.com/retrieve/pii/S0883540311003342

12. Hothi HS, Eskelinen AP, Berber R, Lainiala OS, Moilanen TPS, Skinner JA, et al. Factors Associated With Trunnionosis in the Metal-on-Metal Pinnacle Hip. J Arthroplasty [Internet]. 2017 Jan [cited 2017 Apr 24];32(1):286-90. Available from: http://www.ncbi.nlm.nih.gov/pubmed/27471212
13. Atrey A, Hart A, Hussain N, Waite J, Shepherd AJ, Young S. 601 metal-on-metal total hip replacements with $36 \mathrm{~mm}$ heads a 5 minimum year follow up: Levels of ARMD remain low despite a comprehensive screening program. J Orthop [Internet]. 2017 Mar [cited 2017 Apr 24];14(1):108-14. Available from: http://www. ncbi.nlm.nih.gov/pubmed/27829734

14. Griffin WL, Fehring TK, Kudrna JC, Schmidt RH, Christie MJ, Odum SM, et al. Are Metal Ion Levels a Useful Trigger for Surgical Intervention? J Arthroplasty [Internet]. 2012 Sep [cited 2018 Feb 9];27(8):32-6. Available from: http://www. ncbi.nlm.nih.gov/pubmed/22608683

15. Clarke MT, Lee PTH, Arora A, Villar RN. Levels of metal ions after small- and large-diameter metal-on-metal hip arthroplasty. J Bone Joint Surg Br [Internet]. 2003 Aug 1 [cited 2019 Jul 3];85-B(6):913-7. Available from: http://online.boneandjoint.org.uk/doi/10.1302/0301-620X.85B6.14166

16. Campbell PA, Kung MS, Hsu AR, Jacobs JJ. Do Retrieval Analysis and Blood Metal Measurements Contribute to Our Understanding of Adverse Local Tissue Reactions? Clin Orthop Relat Res [Internet]. 2014 Dec 27 [cited 2017 Apr 26];472(12):3718-27. Available from: http://www.ncbi.nlm.nih.gov/ pubmed/25160942

17. Fehring TK, Fehring K, Odum SM. Metal Artifact Reduction Sequence MRI Abnormalities Occur in Metal-on-polyethylene Hips. Clin Orthop Relat Res [Internet]. 2015 Feb 21 [cited 2017 Apr 26];473(2):574-80. Available from: http://www. ncbi.nlm.nih.gov/pubmed/25141843

18. Jennings JM, Martin JR, Kim RH, Yang CC, Miner TM, Dennis DA. Metal Artifact Reduction Sequence MRI Abnormalities in Asymptomatic Patients with a Ceramic-on-Polyethylene Total Hip Replacement. J Bone Jt Surg [Internet]. 2017 Apr 5 [cited 2017 Apr 26];99(7):593-8. Available from: http://www.ncbi.nlm.nih. gov/pubmed/28375892

19. Goldstein JM, Fehring TK, Fehring KA. Cystic Adverse Local Tissue Reactions in Asymptomatic Modular Metal-on-Metal Total Hips May Decrease Over Time. J Arthroplasty [Internet]. 2016 Jul [cited 2017 Apr 26];31(7):1589-94. Available from: http://www.ncbi.nlm.nih.gov/pubmed/26900148

\section{SUBMISSION HISTORY}

Submitted: May 2, 2019

Reviewed: June 9, 2019

Revised: July 10, 2019

Accepted: June 2, 2019

Published: November 12, 2019

AUTHOR AFFILIATIONS

1 J. Ryan Martin, MD; William Griffin, MD OrthoCarolina, Hip and Knee Center, Charlotte, NC - USA

2 Susan M. Odum, PhD OrthoCarolina Research Institute, Charlotte, NC - USA

(Direct inquires to Ryan Martin, johrmart@gmail.com)

\section{AUTHOR DISCLOSURES}

The authors declare that there are no disclosures regarding the publication of this paper.

\section{COPYRIGHT \& OPEN ACCESS}

(C) 2019 Martin, Odum, Griffin. All rights reserved. Authors retain copyright and grant the journal right of first publication with the work Reconstructive Review is an open access publication and follows the Creative Commons Attribution-NonCommercial CC BY-NC. This license allows anyone to download works, build upon the material, and share them with others for non-commercial purposes as long as they credit the senior author, Reconstructive Review, and the Joint Implant Surgery \& Research Foundation (JISRF). An example credit would be: "Courtesy of (senior author's name), Reconstructive Review, JISRF, Chagrin Falls, Ohio". 
Signature Orthopaedics France L'Arobase - 2 Rue Georges Charpak 81100 CASTRES
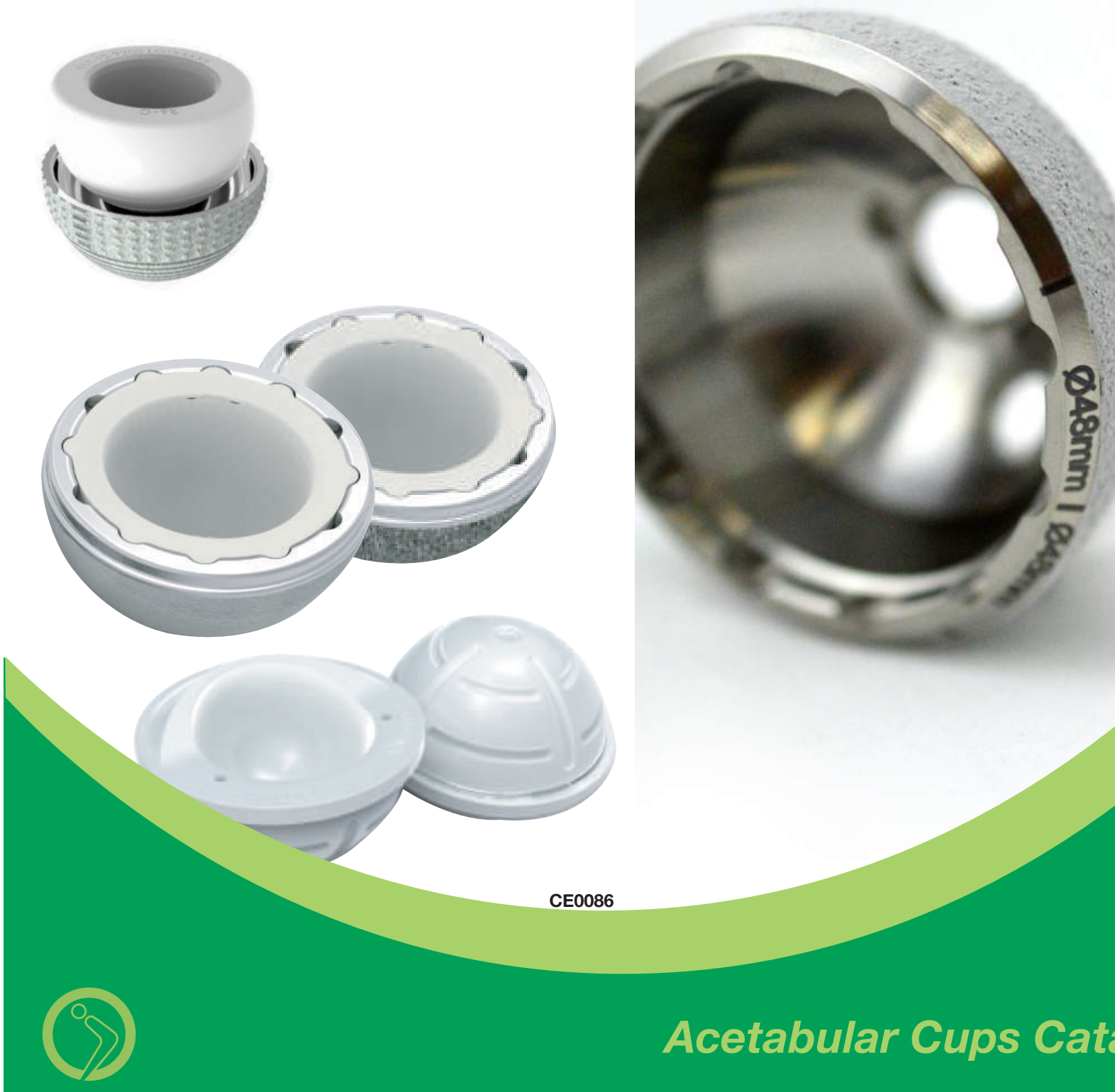

\section{Acetabular Cups Catalogue}

000-000-000

Signature Orthopaedics Europe 88 Harcourt St Dublin Ireland T+353 $16915293 \mathrm{~F}+35316915010$
Signature Orthopaedics Australia

7 Sirius Rd Lane Cove West NSW Australia

T+61 294285181 F+61 284566065

info@signatureortho.com.au

www.signatureortho.com.au 